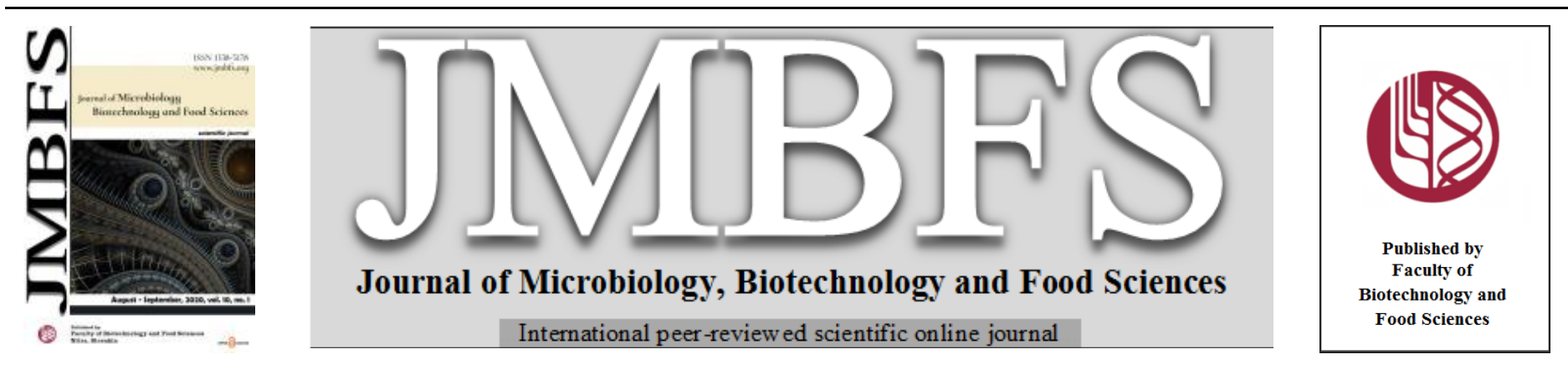

\title{
EFFICACY OF LEMON GRASS (CYMBOPOGON CITRATUS STAPF.) ESSENTIAL OIL AS A NATURAL PRESERVATIVE IN READY-TO-DRINK MORINGA (MORINGA OLEIFERA LAM.) BEVERAGE
}

\author{
Gene Christian P. Romuga ${ }^{1,2}$, Rona Camille M. Lizardo ${ }^{2,3}$ \\ Address(es): Rona Camille M. Lizardo, M.Sc., \\ ${ }^{1}$ Hochschule Anhalt University of Applied Sciences, Department of Applied Biosciences and Process Engineering, Kothen, Saxony, Anhalt Germany. \\ ${ }^{2}$ University of the Philippines Los Baños, College of Agriculture and Food Science, Institute of Food Science and Technology, College, 4031 Los Baños, Laguna, \\ Philippines. \\ ${ }^{3}$ Dong-A University, College of Natural Resources and Life Science, Department of Biotechnology, 37, Nakdongdaero 550beon-gil, 49315 Saha-gu, Busan, Republic \\ of Korea. +821086903068 .
}

*Corresponding author: rmlizardo@up.edu.ph

doi: $10.15414 / j m b f s .2020 .10 .1 .28-32$

\section{ARTICLE INFO}

Received 7. 1. 2019

Revised 20. 2. 2020

Accepted 3. 3. 2020

Published 1. 8. 2020

Regular article open $\bigodot_{\text {ACCESS }}$

\begin{abstract}
Essential oil from a variety of sources has been proven to be effective antimicrobial for the past decades. However, its efficacy when applied to the food system is a major consideration. This study aimed to evaluate the antimycotic property of lemon grass (Cymbopogon citratus Stapf.) essential oil (LGEO) and its effect on the microbial stability and quality of ready-to-drink (RTD) moringa (Moringa oleifera Lam.) beverage. Agar well diffusion assay was used to screen the antimycotic activity of the essential oil against common fungi that may grow in ready-to-drink beverages. The largest zone of inhibition $(10.67 \pm 1.15 \mathrm{~mm})$ was observed against the yeast Debaryomyces hansenii. It was followed by Hansenula anomala and Torulopsis candida with zones of inhibition of $5.67 \pm 0.58 \mathrm{~mm}$ and $3.67 \pm 0.58 \mathrm{~mm}$, respectively. For molds, Penicillium roqueforti and Mucor rouxii were reported to have $2.33 \pm 0.58 \mathrm{~mm}$ and $2.00 \pm$ $1.00 \mathrm{~mm}$ zones of inhibition, respectively. Agar dilution method was performed to determine the minimum inhibitory concentration (MIC) against each microorganism. D. hansenii was the most susceptible yeast which was inhibited by $1.5 \mathrm{uL} / \mathrm{mL}$ of LGEO. It was followed by $H$. anomala and $T$. candida which were inhibited at minimum concentrations of $3 \mathrm{uL} / \mathrm{mL}$ and $5 \mathrm{uL} / \mathrm{mL}$, respectively. Microbial count monitoring of moringa beverage containing different concentrations of LGEO was performed within 10 days and 10 $\mathrm{uL} / \mathrm{mL}$ of LGEO was found to be the most effective concentration in maintaining the stability of the beverage. The addition of LGEO combined with heat treatment exhibited a synergistic effect in the preservation of RTD moringa beverage. Sensory evaluation results indicated that addition of LGEO did not negatively affect the organoleptic properties of the drink. Results showed that LGEO is an effective antimycotic agent and a potential natural preservative in RTD moringa beverage.
\end{abstract}

Keywords: natural preservative, lemon grass essential oil, antimycotic agent, moringa beverage

\section{INTRODUCTION}

Ready-to-drink beverages and juices usually have an acidic $\mathrm{pH}$ range, and with this condition, the common microorganisms that cause their spoilage are yeast and molds. Molds can produce mycotoxins in juice such as patulin, which is produced by several species of Penicillium, and ochratoxin A and citrinin produced by other genus of molds (Vasavada, 2003). The most common preservation technique applied in juices is pasteurization. Nevertheless, there are still heat resistant species of mycelia fungi such as several species of Byssochlamys, Monascus, Paecilomyces and Aspergillus which are reported to spoil juices, and at some extent, mycotoxins are produced (Keller and Miller, 2006). Additional techniques include the use of antimicrobial agents which preserve the food by inhibiting the growth of microorganisms and prevent subsequent spoilage by serving as fungistat, mold and rope inhibitor (Jiang, 2009).

Consequently, there has been an increasing demand for processed foods that contain fewer or no synthetic additives. Food manufacturers responded to what the consumers require for the 'natural' food thus, many researches for possible preservatives derived from natural sources were established (Russell and Gould, 1996). The use of natural food preservative is in line with the growing demand in green consumerism. Green consumerism is a set of practices which are primarily focused on sustainable consumption, alleviating the social and environmental effects of consumption, reducing the harmful effects of different commodities on people by consuming green products which are natural rather than those which are synthetically produced (Mansvelt, 2011)

Natural antimicrobials are derived from different sources like plants, animals and microorganisms. They can exhibit antimicrobial activity in the foods by adding them as ingredients or as additives. Chitosan, lysozyme, and lactoperoxidases are examples of antimicrobials from animals. Plant antimicrobials include essential oils, aldehydes, esters, herbs and spices. Nisin, on the other hand, is of microbial origin (Jiang, 2009). Among these natural origins, plants have been considered to be one of the most abundant sources consisting a vast range of compounds with a broad spectrum of biological activities. Such components include alkaloids, dienenes, flavonols, flavones, glycosides, lactones, organic acids, phenolic compounds, and protein among others. These substances have high potential to be utilized as food preservatives (Bhat, 2012).

Lemon grass (Cymbopogon citratus Stapf.) or locally known in the Philippines as 'tanglad' is commonly utilized as a food spice and flavoring,

herbal medicine, and even as scent in cosmetic products. The distinct odor of lemon grass is due to its essential oil. Essential oils are complex mixture of acyclic and/or cyclic terpenoids. These are monoterpenes, lipophilic, volatile substances which gives the characteristic odor of many plants (Croteau, 1987). Lemon grass essential oil was also known to exhibit antimicrobial activity, and its use as a natural preservative in foods is worth to be investigated.

Moringa oleifera, locally known as 'malunggay', on the other hand, is known to contain substantial amount of nutrients essential to health like $\beta$-carotene, ascorbic acid, folic acid and minerals such as iron, calcium, phosphorus and zinc (Simopoulos, 2003). It is commonly utilized as an ingredient in local cooking. Because of the known nutritional value of moringa, it has been incorporated as an ingredient in food supplements and is processed into beverages.

In line with green consumerism and the explorations of new preservation method to further increase the microbial stability of juices, processors tend to find more natural ways in preserving food. Essential oil is of plant origin and is considered as Generally Recognized as Safe (GRAS) for its intended use (USFDA, 2019). In the present study, the application of lemon grass essential oil to an arising 
beverage, ready-to-drink moringa juice, as a natural antimycotic agent was investigated.

\section{MATERIALS AND METHODS}

\section{Plant material}

Fresh lemon grass (Cymbopogon citratus Stapf.) was procured from Nagcarlan, Laguna, Philippines. The roots and soil particles were removed, and the plant material was washed thoroughly, air dried and kept in dark at $25^{\circ} \mathrm{C}$ until use.

\section{Extraction of essential oil}

Dried lemon grass leaves were crushed using Osterizer blender (Oster Manufacturing, Florida, USA) and mixed with acetic acid-sodium acetate buffer at $\mathrm{pH} 4.5$ with 1:3 (lemon grass : buffer) ratio. After mixing, $1 \%(\mathrm{v} / \mathrm{w})$ of the enzyme cellulase obtained from the National Institute of Molecular Biology and Biotechnology, University of the Philippines Los Baños was added in the mixture. Enzyme-aided extraction was performed by allowing it to stand at $30^{\circ} \mathrm{C}$ for 24 hours. The resulting mixture was filtered and added with $5 \mathrm{~mL}$ of petroleum ether per $250 \mathrm{~mL}$. The solvent was evaporated from the organic layer and the extract was concentrated using rotary evaporator. The lemon gras essential oil (LGEO) was filtered over anhydrous $\mathrm{Na}_{2} \mathrm{SO}_{4}$, collected and stored in dark at $4^{\circ} \mathrm{C}$ until use.

\section{Microbial cultures}

Pure cultures of representative microorganisms that may proliferate in the acidic environment of juices and beverages such as Debaryomyces hansenii, Hansenula anomala, Torulopsis candida, Penicillium roqueforti and Mucor rouxii were obtained from the Food Microbiology Laboratory, Institute of Food Science and Technology, University of the Philippines Los Baňos. All cultures were maintained in Potato Dextrose Agar (PDA) slants and kept at $4^{\circ} \mathrm{C}$ until needed.

\section{Agar well diffusion assay}

In order to determine the antimycotic property of the extracted LGEO, agar well diffusion assay was performed based on the method of Helal et al., (2006) against the test organisms. Different amounts of essential oil $(20,40$ and $60 \mathrm{uL})$ were placed in holes and sterile water containing $0.5 \%$ Tween 80 was used as the control. After the complete diffusion of essential oil in the agar, the plates were incubated at $30^{\circ} \mathrm{C}$ for 3 and 5 days for yeast and molds, respectively, and the diameter of the zones of inhibition was measured using a Vernier caliper (Mitutoyo Corporation, Japan) and was expressed in $\mathrm{mm}$.

\section{Determination of minimum inhibitory concentration (MIC)}

Modified procedure based on the method of Tyagi \& Malik (2010) was used in the determination of MIC. PDA with different concentrations of essential oil (10, $5,4,3,2,1.5$ and $1 \mathrm{uL} / \mathrm{mL}$ ) were prepared. Each tube, which contained $500 \mathrm{uL}$ of $0.5 \%$ Tween 80 and $65 \mathrm{uL}$ of $10 \%$ tartaric acid, was inoculated with $150 \mathrm{uL}$ of $10^{6} \mathrm{cfu} / \mathrm{mL}$ cell suspension.,. The test tubes were incubated at $30^{\circ} \mathrm{C}$ for 3 and 5 days for yeast and molds, respectively. The lowest concentration of essential oil where no colony was observed after incubation was recorded as the minimum inhibitory concentration.

\section{Food application}

\section{Moringa beverage formulation}

The formulation of the ready-to-drink beverage included moringa leaves extract, 'calamansi' extract as acidifier and refined sugar. The mixture was added with $1 \%$ of soybean lecithin to serve as emulsifier. Moringa beverage with lemon grass essential oil as preservative at a concentration of 5 and $10 \mathrm{uL}$ per mL beverage, was prepared. The $\mathrm{pH}$ and total soluble solids were adjusted to 4.5 and $6{ }^{\circ} \mathrm{Brix}$, respectively, and the ready-to-drink beverage was pasteurized at $80^{\circ} \mathrm{C}$ for 15 minutes.

\section{Microbial analysis}

Yeasts and molds in the normal flora of the packaged ready-to-drink beverage were monitored within 10 days of storage at ambient condition. Fungal counts of different treatments namely pasteurized beverage containing LGEO at 5 and 10 $\mathrm{uL}$ per $\mathrm{mL}$ of beverage and unpasteurized beverage containing the same amount of LGEO, were determined using spread plating technique. Pasteurized and unpasteurized beverages without the LGEO were used as the control. The microbial count was calculated using the formula,

$$
\frac{C F U}{m L}=\frac{\Sigma C}{[(n 1 x 1)+(n 2 x 0.1)] x d}
$$

where, $\mathrm{CFU} / \mathrm{mL}=$ colony forming unit per $\mathrm{mL}$ of sample; $\mathrm{C}=$ number of colonies in the counted plates; $\mathrm{n} 1$ and $\mathrm{n} 2$ are the number of plates counted for two consecutive dilutions with valid counts; and $\mathrm{d}=$ dilution from which $\mathrm{n} 1$ was obtained. The valid count ranges considered were 25-250 for molds and 35-350 for yeasts and the microbial load was expressed as log of CFU/mL.

\section{Sensory evaluation}

To determine whether the addition of lemon grass essential oil could affect the sensory characteristics of the beverage, sensory evaluation was performed (Watts et al., 1989). The intensity of sensory characteristics namely color, aroma, sweetness, sourness, flavor, as well as the general acceptability of the moringa beverage with the different concentrations of essential oil were assessed by 20 laboratory panelists using quality scoring in a 6-in line scale. Samples were evaluated at room temperature $\left(25^{\circ} \mathrm{C}\right)$ under white lighting condition in separate sensory evaluation booths.

\section{Statistical analysis}

All analyses were carried out in triplicates. Randomized complete block design was employed for agar well diffusion experiment and determination of minimum inhibitory concentration. For the experiments on the juice application of essential oil, two factorial experimental design was used. The data gathered from the experiments were subjected to the Analysis of Variance (ANOVA) and analyzed using SAS General Linear Models (GLM) procedure with SAS software 9.1.3. Least Significant Difference (LSD) test was performed to determine if there are significant differences among treatments. For the sensory evaluation results, Duncan's New Multiple Range Test (DNMRT) was used to locate which treatments are significantly different from each other. Difference was defined at $\mathrm{p}<0.05$ level of significance.

\section{RESULTS AND DISCUSSION}

\section{Antimycotic activity of lemon grass essential oil}

The antifungal activity of lemon grass essential oil (LGEO) was assessed by the presence or absence of inhibition zones against the selected yeasts and molds. Three different amounts of essential oil were used (20, 40 and $60 \mathrm{uL}$ ) with $0.5 \%$ $\mathrm{v} / \mathrm{v}$ Tween 80 as control. Inhibition at $60 \mathrm{uL}$ for Torulopsis candida was the highest $(3.67 \pm 0.58 \mathrm{~mm})$. For Debaryomyces hansenii, all treatments showed significant differences with each other. The highest inhibition was observed at 60 $\mathrm{uL}(10.67 \pm 1.15 \mathrm{~mm})$ followed by $40 \mathrm{uL}(7.33 \pm 0.58 \mathrm{~mm})$ and $20 \mathrm{uL}(4.67 \pm 0.58$ $\mathrm{mm}$ ). There was no significant difference in the zones of inhibition exhibited by $60 \mathrm{uL}$ and $40 \mathrm{uL}$ of LGEO against Hansenula anomala which measured $5.67 \pm 0.58 \mathrm{~mm}$ and $5.00 \pm 0.00 \mathrm{~mm}$, respectively. For molds, no significant differences in the zones of inhibition were observed in all amounts of LGEO against Mucor rouxii. Small clearings of inhibition were measured, $2.00 \pm 1.00$ $\mathrm{mm}$ at $60 \mathrm{uL}, 1.67 \pm 0.58 \mathrm{~mm}$ at $40 \mathrm{uL}$ and $1.33 \pm 0.58 \mathrm{~mm}$ at $20 \mathrm{uL}$. Similar result was observed in Penicillium roqueforti which registered no significant differences among amounts of LGEO. Measure of the zones of inhibitions were $2.33 \pm 0.58 \mathrm{~mm}$ at $60 \mathrm{uL}, 2.00 \pm 1.00 \mathrm{~mm}$ at $40 \mathrm{uL}$ and $1.67 \pm 0.58 \mathrm{~mm}$ at $20 \mathrm{uL}$. In general, the zone of inhibition increased in a dose-dependent manner. Results also showed that yeasts exhibited more susceptibility than molds as presented on table 1 . 
Table 1 Zone of inhibition by different concentrations of lemon grass essential oil against selected microorganism

\begin{tabular}{|c|c|c|c|c|}
\hline \multirow[t]{2}{*}{ Microorganism } & \multicolumn{4}{|c|}{ Zone of inhibition, $\mathbf{m m}^{1}$} \\
\hline & Control $(0.5 \%$ v/v Tween 80$)$ & $20 \mathrm{uL}$ & $40 \mathrm{uL}$ & $60 \mathrm{uL}$ \\
\hline Torulopsis candida & $0.00 \pm 0.00^{c}$ & $0.67 \pm 0.58^{\mathrm{bc}}$ & $1.00 \pm 0.00^{\mathrm{b}}$ & $3.67 \pm 0.58^{\mathrm{a}}$ \\
\hline Debaryomyces hansenii & $0.00 \pm 0.00^{\mathrm{d}}$ & $4.67 \pm 0.58^{\mathrm{c}}$ & $7.33 \pm 0.58^{\mathrm{b}}$ & $10.67 \pm 1.15^{\mathrm{a}}$ \\
\hline Hansenula anomala & $0.00 \pm 0.00^{\mathrm{c}}$ & $2.67 \pm 0.58^{b}$ & $5.00 \pm 0.58^{\mathrm{a}}$ & $5.67 \pm 0.58^{\mathrm{a}}$ \\
\hline Mucor rouxii & $0.00 \pm 0.00^{\mathrm{b}}$ & $1.33 \pm 0.58^{\mathrm{ab}}$ & $1.67 \pm 0.58^{\mathrm{a}}$ & $2.00 \pm 1.00^{\mathrm{a}}$ \\
\hline Penicillium roqueforti & $0.00 \pm 0.00^{\mathrm{b}}$ & $1.67 \pm 0.58^{\mathrm{a}}$ & $2.00 \pm 1.00^{\mathrm{a}}$ & $2.33 \pm 0.58^{\mathrm{a}}$ \\
\hline
\end{tabular}

${ }^{1}(\mathrm{~N}=3)$ Means followed by the same letter within each row are not significantly different from each other at $\mathrm{p}<0.05$ using LSD.

Monoterpenoids and oxygenated terpenes were the most dominant components of LGEO (Bassole et al., 2011). Among these compounds, citral, a major constituent in essential oil of Cymbopogon species, was reported to have a strong antimicrobial activity against plant and human pathogens Redov et al. (1995) Other identified major compounds in lemongrass essential oil which could have contributed to its potential antimicrobial activity are limonene, geranyl acetate and $\beta$-caryophyllen. The presence of these substances effectively inhibited certain foodborne pathogens such as Escherichia coli, Salmonella typhimurium albicans, Bacillus cereus and Staphylococcus aureus at a relatively low MIC of $0.5 \mu \mathrm{L} / \mathrm{mL}$ (Vaziriana et al., 2012). Most studies have described the greater susceptibility of bacteria to LGEO and its components in comparison to molds and yeasts (Helal, 2006). On the contrary, the findings of Singh et al., (2011) have shown the relative sensitivity of certain yeasts, particularly Candida albicans, to LGEO at a MIC of $1.0 \mu \mathrm{L} / \mathrm{mL}$. Furthermore, geraniol, a lemon grass essential oil constituent, attacks the yeast cells causing an excessive $\mathrm{K}+$ ion leakage. This induces alterations in cell membrane composition by increasing the proportion of saturated fatty acid and decreasing the unsaturated one as exemplified by the same study on Saccharomyces cerevisiae (Ganjewala \& Gupta, 2013).

The effect of LGEO on molds is primarily based on its ability to alter its morphological characteristics. In a study by Yousef (2013), Aspergillus niger, as a representative, had shown some morphological changes after the treatment of LGEO. These changes included decrease in sporulation, less pigmentation and reduction and distortion of conidiophores. It should also be noted that the effects of LGEO on fungal morphology causing its inhibition varies from species to species, and specific study is needed to determine the effect on particular test organisms.

\section{Minimum inhibitory concentration}

The minimum inhibitory concentration (MIC) of LGEO against the different test organisms with initial count of $10^{6} \mathrm{cfu} / \mathrm{mL}$ was determined using the agar dilution method. In this case, the lowest concentration of essential oil, in which no colony formation was observed on the agar media, was considered the MIC. $M$. rouxii and $P$. roqueforti had the least susceptibility to LGEO, with MIC of $>10 \mathrm{uL} / \mathrm{mL}$, among test organisms. This observation was parallel to its zone of inhibition with a low value implying that a higher amount of EO is needed to inhibit the microorganism. On the other hand, yeasts had a lower MIC compared to molds. Among the yeasts used in this experiment, T. candida was the least susceptible with MIC of $5 \mathrm{uL} / \mathrm{mL}$. followed by $H$. anomala with MIC of $3 \mathrm{uL} / \mathrm{mL}$ while $D$. hansenii was inhibited by $\mathrm{LGEO}$ at $\mathrm{MIC}$ of $1.5 \mathrm{uL} / \mathrm{mL}$. It was noted that $D$. hansenii was the most susceptible to LGEO as identified through its zone of inhibition, implying that low concentration of LGEO is needed to inhibit the microorganism. Results are shown on table 2 .

Table 2 Minimum inhibitory concentration of lemon grass essential oil against the test organisms.

\begin{tabular}{ll}
\hline Test organism & MIC, $\mathbf{u L} / \mathbf{m L}$ \\
\hline T. candida & $5 \pm 0.08$ \\
D. hansenii & $1.5 \pm 0.07$ \\
H. anomala & $3 \pm 0.12$ \\
P. roquefortii & $>10$ \\
M. rouxii & $>10$ \\
\hline
\end{tabular}

These results are in accordance to the studies on the minimum inhibitory concentration of several essential oils against specific test organisms as reported by Krisch et al. (2011). Specific yeasts are inhibited at lower concentration of essential oil as compared with molds. For instance, MIC values of cumin, cassia, allspice and thyme against the tested yeasts Candida species and $S$. cerevisiae were in the range of $0.04 \mu \mathrm{l} / \mathrm{ml}$ and $1.25 \mu \mathrm{l} / \mathrm{ml}$ (Kamble and Patil, 2008). Meanwhile, molds such as Aspergillus flavus and A. niger were inhibited at MIC of $\geq 20,000 \mu \mathrm{l} / \mathrm{ml}$ (Carmo et al., 2008).

\section{Food application}

\section{Microbial stability of moringa juice with lemon grass essential oil}

In order to evaluate the effect of addition of LGEO on the growth of inherent microorganisms in moringa juice, unpasteurized juice with 5 and $10 \mathrm{uL} / \mathrm{mL}$ LGEO was prepared. As shown in figure 1A, yeast and mold count of moringa juice without LGEO increased from $1.8 \log \mathrm{cfu} / \mathrm{mL}$ to $23.2 \log \mathrm{cfu} / \mathrm{mL}$ after the completion of the sampling period. Moringa beverage containing $5 \mathrm{uL} / \mathrm{mL}$ LGEO exhibited only $1.0 \log \mathrm{cfu} / \mathrm{mL}$ increase in the yeast count at the end of the sampling period. Meanwhile, the moringa beverage with $10 \mathrm{uL} / \mathrm{mL}$ of $\mathrm{EO}$ exhibited a decrease in the number of yeast cells from $1.6 \log \mathrm{cfu} / \mathrm{mL}$ to $1.1 \mathrm{log}$ $\mathrm{cfu} / \mathrm{mL}$
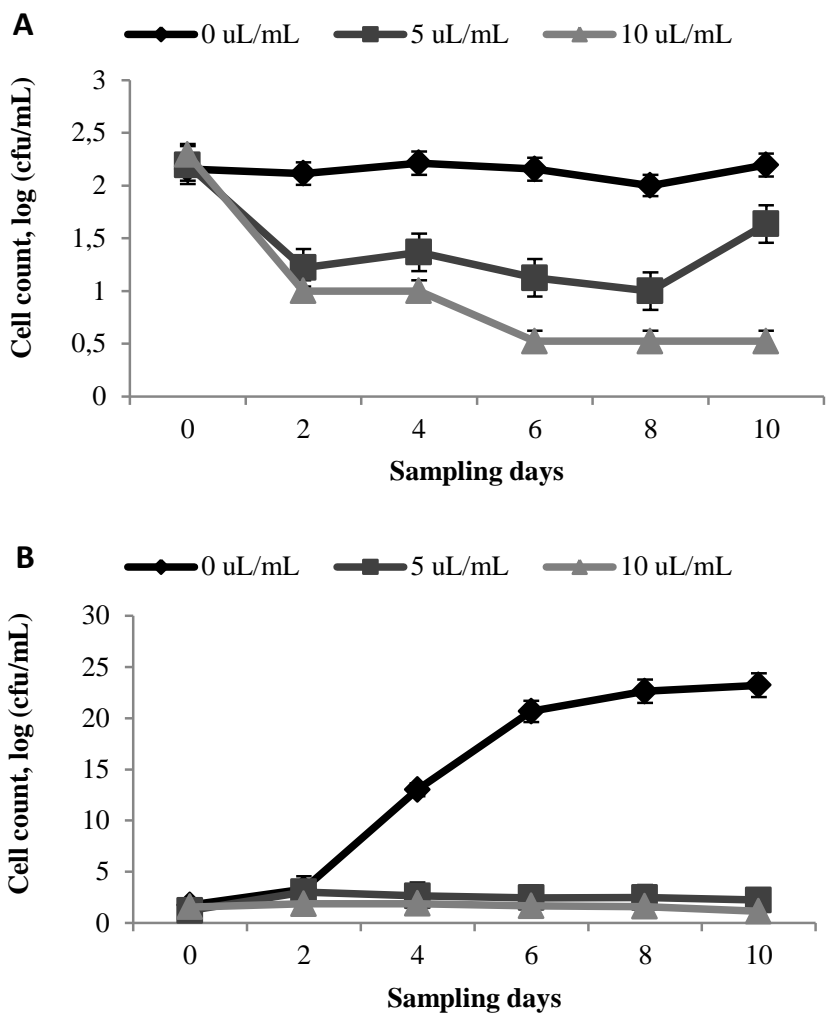

Figure 1 Yeast and mold count of (A) unpasteurized and (B) pasteurized moringa juice during the sampling period.

The effect of LGEO as a natural antimycotic agent in pasteurized moringa juice was also determined. There was no significant change observed in the yeast and mold count of the control (juice without LGEO) throughout the sampling period (Figure 2B). A reduction from $2.2 \mathrm{log} \mathrm{cfu} / \mathrm{mL}$ to $1.6 \mathrm{log} \mathrm{cfu} / \mathrm{mL}$ was observed in the juice with $5 \mathrm{uL} / \mathrm{mL}$ of LGEO. The microbial count of the juice with 10 $\mathrm{uL} / \mathrm{mL}$ of LGEO was reduced from $2.3 \log \mathrm{cfu} / \mathrm{mL}$ to $0.5 \log \mathrm{cfu} / \mathrm{mL}$.

The result of this experiment showed that lemon grass essential oil can prevent the proliferation of yeast and molds that may cause spoilage of the moringa juice and could help prolong its shelf stability even without heat treatment. The findings also signified that addition of LGEO caused a significant reduction on the number of yeast and mold count in the pasteurized RTD moringa juice.

According to Krisch et al. (2011), the antifungal activity of essential oil is often influenced by external factors specifically water activity and temperature. Higher water activity results in greater inhibition of yeast and mold. Also, the effect of temperature on the target microorganism is more pronounced at higher water activity. In the study conducted by Beletti et al. (2007), the combination of linalool and $\beta$-pinene, together with a mild $\left(55^{\circ} \mathrm{C}\right)$ heat treatment resulted in the 
lower spoilage probability in citrus based non-carbonated beverages. In this experiment, it was also demonstrated that lemon grass essential oil can act synergistically with heat treatment in prolonging the microbial stability of the RTD moringa beverage.

\section{Sensory evaluation of moringa beverage with lemon grass essential oil as natural preservative}

Sensory attributes namely color, aroma, sweetness, sourness, and flavor, as well as the general acceptability of moringa juice with 5 and $10 \mathrm{uL} / \mathrm{mL}$ LGEO were assessed and results are presented on table 3 .

Table 3 Sensory characteristics of moringa beverage with lemon grass essential oil

\begin{tabular}{lccc}
\hline \multirow{2}{*}{ Attribute } & \multicolumn{3}{c}{ Mean Sensory Scores $^{\mathbf{1}}$} \\
\cline { 2 - 4 } & Control & $\mathbf{5} \mathbf{~ u L / m L}$ & $\mathbf{1 0} \mathbf{~ u L} / \mathbf{m L}$ \\
\hline Color $^{\mathrm{ns}}$ & 5.00 & 5.01 & 4.93 \\
Aroma $^{\text {Sourness }}{ }^{\mathrm{ns}}$ & $1.00^{\mathrm{b}}$ & $2.01^{\mathrm{a}}$ & $2.33^{\mathrm{a}}$ \\
Sweetness $^{\mathrm{ns}}$ & 2.33 & 2.53 & 2.60 \\
Flavor $^{\text {General }}$ & 3.33 & 3.47 & 3.27 \\
Acceptability $^{\mathrm{ns}}$ & $1.40^{\mathrm{c}}$ & $2.67^{\mathrm{b}}$ & $3.33^{\mathrm{a}}$ \\
& 3.13 & 3.07 & 3.27
\end{tabular}

${ }^{1}(\mathrm{~N}=20)$ Means followed by the same letter within each row are not significantly different from each other at $\mathrm{p}<0.05$ using DNMRT

Range of scores: Color: $0=$ light, $6=$ dark; Aroma: $0=$ weak, $6=$ strong; Sourness $0=$ weakly perceptible, $6=$ strongly perceptible; Sweetness: $0=$ not sweet, $6=$ very sweet; Flavor: $0=$ weak, $6=$ strong; General acceptability: $0=$ not acceptable $6=$ very acceptable

The evaluated sensory attributes were the common characteristics perceived by most consumers on products like juices and alteration in such attributes may affect the acceptability of the product. Specifically, the flavor, taste and aroma are usually affected by the addition of ingredients such as essential oil due to characteristic odor that this component may impart to the food product. In the conducted sensory evaluation, the laboratory panelists did not perceive significant differences $(\mathrm{p}<0.05)$ in color, sweetness and sourness of the ready-todrink moringa beverage. On the other hand, in terms of flavor, samples with LGEO significantly differed from each other as well as from the control. The lemon grass aroma was also detected in the samples. The juice sample with 5 $\mathrm{uL} / \mathrm{mL}$ of EO did not significantly differ from the sample with $10 \mathrm{uL} / \mathrm{mL}$ in terms of lemon grass aroma. Consequently, the addition of LGEO did not significantly affect the general acceptability of the RTD moringa beverage. Hence, addition of a potent concentration of LGEO in the RTD moringa juice as natural antimicrobial did not negatively affect its sensory characteristics as perceived by the panelists.

In the research conducted by Tserennadmid et al. (2011), lemon oil was used as an antimicrobial in apple juice to extend its 'open' shelf life. It was found that the growth of the fermentative yeasts Saccahromyces cerevisiae and S. pombe was significantly halted, particularly in clear apple juice, while the lemon oi harmoniously blended with the flavor of the apple juice and added to its refreshing taste as perceived by the sensory panelists. Based on the study of Beletti et al. (2011) as cited by Krisch $\boldsymbol{e t}$ al. (2011), the addition of essential oil components at concentrations 40 and $60 \mu \mathrm{l} / \mathrm{L}$ had no negative effect on the flavor of the beverages and the mild thermal treatment employed which was below the usual temperature range $\left(65-75^{\circ} \mathrm{C}\right)$ reduced the energy costs in the production of the beverages. Meanwhile, addition of $500 \mathrm{ppm}$ thyme essential oil in tomato paste reduced the growth of A. flavus by $87 \%$ while the taste was still acceptable to the consumer panel (Omidbeygi et al., 2007).

Assessment of the effect of the incorporation of essential oils, to serve as preservative, on the organoleptic properties of actual food products is essential as these components may have significant impact on the sensory attributes as well as the overall acceptability. It is an important consideration to maintain the overall quality of the food product in terms of sensory properties while keeping it safe for consumption.

\section{CONCLUSION}

The results of this study highlighted the effectiveness of lemon grass essential oi as an antimycotic agent against target microorganisms that may commonly survive in a food system specifically juice and beverages. The lemon grass essential oil was found to be specifically effective against the yeasts which were tested in the experiments. Also, minimum concentrations of $1.5-3.0 \mathrm{ul} / \mathrm{ml}$ were potent enough to inhibit the growth of the targeted yeasts. Upon application of the lemon grass essential oil in the formulated ready-to-drink moringa beverage, the findings showed its efficacy as a natural preservative as it repressed the proliferation of the yeasts and molds present in the juice without causing a negative impact on the organoleptic properties as well as the general acceptability of the beverage. This study also revealed the potential application of lemon gras essential oil in combination with other preservation technologies such as thermal treatment or as a natural preservative in cold-pressed or unpasteurized juices to prolong their shelf-life.

Acknowledgment: The authors would like to extend their gratitude to the Institute of Food Science and Technology, College of Agriculture and Food Science, University of the Philippines Los Baños for providing the technical support necessary to make this research possible.

\section{REFERENCES}

Bassolé, I. H. N., LamienMeda A., Bayala, B., Obame, L. C., Ilboudo, A. J., Franz, C., Novak, ... \& Dicko, M. H. (2011) Chemical composition and antimicrobial activity of Cymbopogon citratus and Cymbopogon giganteus essentialoils alone and in combination. Phytomedicine, 18, 1070-1074 https://10.1016/j.phymed.2011.05.009

Bhat, R. (2012). Progress in food preservation. Chichester: Wiley-Blackwell $514 \mathrm{p}$.

Beletti, N., Sado Kamden, S., Patrignani, F., Lanciotti, R., Covelli, A., Gardini, F. (2007). Antimicrobial activity of aroma compounds against Saccharomyces cerevisiae and improvement of microbiological stability of soft drinks as assessed by logistic regression. Applied and Environmental Microbiology, 73, 5580-5586 http://dx.doi.org/10.1128/AEM.00351-07

Beletti, N., Sado Kamden, S., Tabanelli, G., Lanciotti, R., Gardini, F. (2010). Modeling of combined effects of citral, linalool and $\beta$-pinene used agains Saccharomyces cerevisiae in citrus-based beverages subjected to a mild heat treatment. International Journal of Food Microbiology, 136, 283-289. http://dx.doi.org/10.1016/j.ijfoodmicro.2009.10.030

Carmo, E. S., de Oliveira Lima, E., de Souza, E. L. (2008). The potential of Origanum vulgare (Lam.) essential oil in inhibiting the growth of some foodrelated Aspergillus species. Brazilian Journal of Microbiology, 39, 362-367. http://dx.doi.org/10.1590/S1517-83822008000200030

Croteau, R. (1987). Biosynthesis and catabolism of monoterpenoids. Chemical Reviews, 87, 929-954. http://dx.doi.org/10.1021/cr00081a004

Helal, G. A. (2006). Antimicrobial activity of some essential oils against microorganisms deteriorating fruit juices. Palestine: Al Azhar University. pp. 219-229

Jiang, L. (2009). Comparison of disk diffusion, agar dilution and broth microdilution for antimicrobial susceptibility testing of five chitosans. M. S. Thesis, Fujian Agricultural and Forestry University, China

Kamble, V. A., Patil, S. D. (2008). Spice-derived essential oils: effective antifungal and possible therapeutic agents. Journal of Herbs, Spices and Medicinal Plants, 14, 129-143. https://doi.org/10.1080/10496470802598677

Keller, S. E., Miller, A. J. (2005). Microbiological safety of fresh citrus and apple juices. Microbiology of fruit and vegetables. Boca Raton, FL: CRC Press Taylor and Francis Group, pp. 211-224. ISBN 9780849322617.

Krisch, J., Tserennadmid, R., Vágvölgyi, C. (2011). Essential oils against yeasts and molds causing food spoilage. Science against microbial pathogens. communicating current research and technological advances. Méndez-Vilas, A (Ed.). Spain: Formatex Research Center, pp. 1135-1142. ISBN (13): 978-84939843-2-8.

Mansvelt, J. (2011). Green consumerism: An A-to-Z guide. Los Angeles: Sage Reference. Print. pp. 154-158.

Omidbeygi, M., Barzegar, M., Hamidi, Z., Nghdibadi, H. (2007). Antifungal activity of thyme, summer savory and clove essential oil against Aspergillus flavus in liquid medium and tomato paste. Food Control, 18, 1518-1523. http://dx.doi.org/10.1016/j.foodcont.2006.12.003

Russel, N. J. and Gould, G. W. (1996). Food preservatives. Springer. New York p.262.

Simopoulos, A. (2003). Plants in human health and nutrition policy. Basel Karger. pp.44-46

Singh, B. R., Singh, V., Singh, R. K. \& Ebibeni, N. (2011). Antimicrobial activity of lemongrass (Cymbopogon citratus) oil against microbes of environmental, clinical and food origin. International Research of Pharmacy and Pharmacology, 1(9), 228-236.

Tserennadmid, R., Takó, M., Galgóczy, L., Papp, T., Pesti, M., Vágvölgyi, C.S., Almássy, K., \& Krisch, J. (2011). Anti-yeast activities of some essential oils in growth medium, fruit juices and milk. International Journal of Food Microbiology, 144, 480-486. http://dx.doi.org/10.1016/j.ijfoodmicro.2010.11.004.

Tyagi, A. K., Malik, A. (2010). Liquid and vapour-phase antifungal activities of selected essential oils against Candida albicans: microscopic observations and chemical characterization of Cymbopogon citratus. BMC Complementary and Alternative Medicine, 10:65. http://dx.doi.org/10.1186/1472-6882-10-65 United States Food and Drug Administration. (2019). Code of federal regulations: Food for human consumption. USFDA, Maryland, USA https://www.accessdata.fda.gov/scripts/cdrh/cfdocs/cfcfr/CFRSearch.cfm?fr=182 .20

Vasavada, P. C. (2003). Microbiology of fruit juice and beverages. Beverage quality and safety. Boca Raton, FL: CRC Press, 248 p. ISBN 9781587160110 
Vaziriana, M., Kashania, S. T., Ardekania, M. R. S., Khanavia, M., Jamalifarb, H., \& Toosi, M. R. F. A. N. (2012) Antimicrobial activity of lemongrass (Cymbopogon citratus (DC) Stapf.) essential oil against food-borne pathogens added to cream-filled cakes and pastries. The Journal of Essential Oil Research, 24:6, 579-582. http://dx.doi.org/10.1080/10412905.2012.729920

Yousef, S.A.A. (2013). Antifungal activity of volatiles from lemongrass (Cymbopogon citratus) and peppermint (Mentha piperita) oils against some respiratory pathogenic species of Aspergillus. Int.J.Curr.Microbiol.App.Sci, 2(6): 261-272. 